\title{
El aprendizaje de las matemáticas elementales como proceso condicionado por la cultura
}

\author{
Carlos Vasco
}

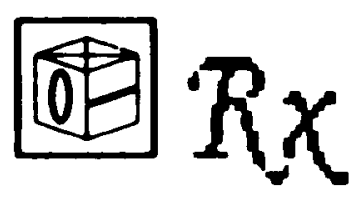

En «El aprendizaje de las matemáticas elementales como proceso condicionado por la cultura», Carlos Vasco examina el "mito" de que las matemáticas son un «lenguaje universal de la ciencia»y, por tanto, una materia supracultural. En sus análisis de casos de niños colombianos, llega a la conclusión de que las matemáticas pueden depender tanto de la cultura como el aprendizaje de la literatura o la bistoria. Según Vasco, la mayoría de los enseñantes cree que los niños no saben nada de matemáticas cuando entran en la escuela; por tanto, la enseñanza de la "matemática moderna" sólo puede llegar a un pequeño porcentaje de los niños. Vasco aduce que sólo los estudiantes que pueden construir sus propios «sistemas conceptuales a pesar de sus maestros" y desentrañar por su cuenta la maraña de sistemas simbólicos serán inmunes a la "fobia a las matemáticas".

\section{INTRODUCCION}

Norma $X$ vive en un barrio pobre que se encuentra en las empinadas colinas al este de Bogotá, Colombia. Cuando la conocí hace seis años, tenia siete años de edad y asistía a una clase de primer curso de una escuela local. Solía ayudar a su madre a vender bocadillos y refrescos los domingos en un parque cercano. Podía vender una dócena de botellas de refresco a nueve pesos la botella y devolver el cambio de un billete de 200 pesos con rapidez y exactitud. Pero suspendió la aritmética de primer curso.

Luis Eduardo $\mathrm{Y}$ abandonó el cuarto curso en 1975. Unos años más tarde qui- so obtener el título de graduado escolar pasando un examen del Estado que se convoca dos veces al año para los aspirantes a matricularse en segunda enseñanza. No se atrevió a presentarse porque pensaba que no sabía nada de fracciones. Pero yo sabía que era un mecánico muy capaz y que era muy experto con tuercas y tornillos, llaves y calibradores. Su mente despierta podía "ver" instantáneamente que una llave de 3/8 de pulgada no podía apretar una tuerca de media pulgada y ni siquiera un tornillo de $1 \mathrm{~cm}$ según las medidas europeas. A mí me hizo falta lápiz y papel para comprobar que tenía razón. Cuando se dio cuenta de que sabía mucho de 
fracciones, pasó sin problemas el examen del Estado y con muy buenas calificaciones. Ahora acaba de finalizar la segunda enseñanza y desea ser enseñante (de matemáticas, claro).

Se cree que la matemática es, de todas las materias académicas, la más independiente de la cultura. En la enseñanza de la mayoría de los países iberoamericanos se emplean textos de "Matemática Modernam impresos en los Estados Unidos o en Bélgica que se traducen al portugués y al castellano con unas mínimas variaciones en los problemas de enunciado verbal. Al mirar hacia atrás veremos que, antes, las cosas no eran distintas: los textos escolares que se solían emplear en Colombia se copiaban unos a otros en una cadena cuyos orígenes se remontaban a la aritmética española o latina del Renacimiento. El mito de las matemáticas como lenguaje universal de las ciencias y la imagen superficial de la verdad matemática como algo inváriablemente estruturado a priori en la razón humana, reforzaban el estereotipo de las matemáticas como materia supracultural.

La distinción entre las cifras romanas y las árabes indicó una medida de dependencia cultural. Pero se pensó que sus causas fueron las primeras etapas de desarrollo de pueblos primitivos, accidentes históricos y el desarrollo tardío de la escritura. Era algo arcaico, situado en un nivel superficial de simbolismo y completamente inmaterial desde el punto de vista de la matemática contemporánea.

Sin embargo, la palabra "arcaico" tiene connotaciones más profundas que la mera obsolescencia. Apunta hacia los orígenes, las fuentes, los principios y los fundamentos. ¿Deberíamos adentrarnos más en las raíces de las matemáticas?

La Arqueologia del conocimiento de Michel de Foucault me enseñó a descubrir estratos ocultos mediante un análisis detallado del discurso. Los verdaderos estudios arqueológicos de Jean Piaget sobre el desarrollo lento y tortuoso de los conceptos matemáticos en los niños, me enseñó a escucharlos con mucha atención y a interpretar sus errores aparentes como síntomas de un tipo distinto de estructura lógica. El psicólogo ruso Lev. A. Vygotsky me enseñó explícitamente por dónde empezar a investigar:

Que el aprendizaje de los niños empieza mucho antes de que asistan a la escue- la es el punto de partida de esta discusión. Todo aprendizaje que emprende un niño en la escuela tiene siempre una historia anterior. Por ejemplo, los niños empiezan a estudiar aritmética en la escuela, pero mucho antes ya han tenido alguna experiencia con las cantidades, es decir, han tenido que tratar con operaciones de división, adición, sustracción y determinación de tamaños. En consecuencia, los niños tienen su propia aritmética preescolar, cosa que sólo los psicólogos miopes pueden ignorar '.

El objetivo de este artículo es determinar de la manera más precisa posible la dependencia cultural del proceso de aprendizaje de las matemáticas. ¿Qué hay de esencialmente correcto en la pretendida universalidad de las matemáticas? ¿Dónde cabe situar los aspectos culturalmente específicos de las matemáticas, tanto en el plano teórico como en el empírico? ¿Cómo se deben emplear para desarrollar un currículo para las matemáticas elementales que esté culturalmente adaptado? Estas son las preguntas que guían la investigación.

\section{EL MARCO CULTURAL}

En Colombia, los programas de primera y segunda enseñanza los establece el Ministerio de Educación siguiendo un criterio centralista y son obligatorios para todos los centros escolares, sean éstos públicos, privados, urbanos o rurales. Las esporádicas reformas realizadas al currículo han consistido en algunas adiciones, eliminaciones y recombinaciones de los contenidos de los programas. En 1975, un Gobierno liberal recientemente elegido inició una reforma escolar exhaustiva denominada «Mejora Cualitativa de la Enseñanza». Se hizo un proyecto de un ambicioso currículo experimental para los tres primeros cursos que se sometió a prueba en una muestra de escuelas repartidas por todo el país. En 1978, la Universidad Nacional de Colombia me desginó Asesor del Ministerio de Educación para la reestructuración de las metemáticas escolares. Desde el primer proyecto se han realizado muchas evaluaciones y nuevas redacciones de los programas experimentales, y se ha enviado un nuevo conjunto de programas para los cinco cursos de la enseñanza elemental a enseñantes y a universidades para que procedan a su evaluación. 
Cerca de la mitad de las escuelas públicas se encuentran en zonas rurales y a las escuelas públicas urbanas sólo asisten estudiantes de clase media-baja y baja. La variedad cultural que se da entre las distintas règiones del país, entre los distritos urbanos y rurales y entre las clases pobres y las clases medias no puede abarcarse adecuadamente con un programa prescrito desde supuestos centralistas, pero la diferenciación (o incluso el «seguimiento") curricular no es factible políticamente. Se ha adoptado una política más. flexible consistente en adaptar los programas a las condiciones locales y éstimular la redacción local de las Unidades Integradas de Aprendizaje; creo que esto es básicamente acertado, pero hace que la evaluación de las pruebas experimentales sea difícil de obtener y aún más difícil de interpretar.

Como era de esperar, los experimentos con los nuevos programas han originado más preguntas que respuestas. $\mathrm{La}$ resistencia de los maestros al cambio está muy generalizada, y los Sindicatos de Enseñantes ponen obstáculos a las reformas como una estrategia para incrementar sus poderes en la mesa de negociaciones. Los grupos de extrema derecha encuentran que los cambios son «peligrosos» (inspirados por el comunismo internacional) y los grupos de extrema izquierda los tildan de «inútiles» o «dictados por el imperialismo yanqui». ' $L a$ investigación local en la educación es mínima y la investigación realizada en otros países suele ser contradictoria o fácilmente descalificada. Se pueden encontrar resultados contradictorios en la mayoría de las cuestiones relativas a la enseñanza de las matemáticas ${ }^{2}$.

La feroz guerra entre la «Matemática Moderna» y el «Retorno a lo fundamental» simplifica en exceso estos temas. Las discusiones son ardorosas y emocionales y los datos esgrimidos por cada bando se vuelven a interpretar con toda facilidad por el otro. Pero en las evaluaciones, en las rencillas políticas, en las investigaciones, $y$ en la polémica entre la «Matemática Moderna» y el «Retorno a lo fundamental» hay una manifiesta ausencia del motivo principal de este artículo: ¿Qué conflictos se plantean entre la matemática universal clásica y los sistemas matemáticos concretos que se encuentran en las culturas locales? ¿Cómo detectar, refinar y utilizar estos sistemas transmitidos culturalmente para una reforma curricular? ¿Qué experiencia con estos sistemas matemáticos concretos poseen ya los niños antes de entrar en la escuela o fuera de ella?

No sólo los psicólogos miopes, sino también casi todo el mundo, suelen dar por sentado de una manera rutinaria que los niños no saben nada de las matemáticas reales cuando entran en la escuela, a excepción, quizá, de contar hasta un número determinado. ¿Qué hay de verdad en esta suposición?

$\mathrm{E}$ incluso los psicólogos perspicaces, y prácticamente todo el mundo, piensan que las matemáticas escolares son un tema universal cuya dependencia cultural se limita al lenguaje informal, los símbolos matemáticos y los ejemplos triviales y problemas de enunciado verbal que se emplean en las clases y en los libros de texto. ¿Estriba en esto la importancia de la dependencia cultural?

\section{UN INSTRUMENTO PARA LA INVESTIGACION CULTURAL EN MATEMATICAS}

Es bien sabido que incluso las culturas no alfabetizadas suelen poseer sistemas de comercio complejos, cálculos astronómicos y de calendario, intricados sistemas de unión con estructuras matemáticas refinadas, etc. Pero ya no es tan sabido que los niños pueden manejar sistemas matemáticos -0 , al menos, protomatemáticos- complejos con gran soltura mucho antes de llegar a la escuela o sin haber asistido nunca a ella.

Muchos resultados dispersos pero coherentes sugerían el desarrollo de un instrumento teórico para abordar los datos empíricos, para establecer el campo con una perspectiva más amplia, para ofrecer un marco de referencia a posteriores investigaciones, para elaborar un lenguaje disciplinado y, sobre todo, para permitir al ojo de la mente una visión más clara de las lagunas o agujeros. En mi opinión, uno de los principales usos de la teoría es la posibilidad de hacer estas lagunas o agujeros más visibles. Por definición, los agujeros son no-entidades y, en consecuencia, no se pueden percibir directamente. El hecho de que alguien los perciba indica la existencia de una teoría subyacente, aunque sólo sea la anticipación de un campo de visión uniforme. Si existe una teoría y se pueden ver sus bordes, se pueden definir lagunas. Si no hay teoría, no hay lagunas. 
Todo el mundo está de acuerdo en que la enseñanza de las matemáticas escolares está llena de lagunas. ¿Cómo clasificarlas y analizarlas? ¿Cómo descartar las pseudolagunas y detectar las nuevas? ¿Cómo percibir los vacíos culturales y la vacuidad pseudo-matemática?

La abusiva moda de «el enfoque de los sistemas" durante los años sesenta, ahora forjada y cincelada por veinte años de duras críticas, aportaba las claves para la comprensión de los sistemas matemáticos impartidos en la escuela y los que eran familiares para los niños en su casa $y$ en su vecindario. Hace falta una versión refinada de una Teoría General de Sistemas aplicable a la investigación de la enseñanza de las matemáticas. Debería abarcar la totalidad de las matemáticas existentes sin ambigüedades pedantes; debería delimitar el campo y ayudar a indicar las lagunas; de manera ideal, debería superar el enfoque centrado en la lógica de conjuntos propio de la $\mathrm{Ma}$ temática Moderna y el enfoque basado en las rutinas numéricas de los seguidores del Retorno a lo fundamental. Pero también debería satisfacer una exigencia aparentemente contradictoria: a pesar de la pretendida generalidad y universalidad, debería ayudar a detectar diferencias culturales muy sútiles en los sitemas protomatemáticos y matemáticos que en realidad usan los niños y los adultos no escolarizados.

A finales de los años setenta intenté desarrollar una versión apropiada de la Teoría General de Sistemas en un marco más general ${ }^{3}$ y refinarla con vistas a la investigación y el desarrollo curricular en matemáticas ${ }^{4}$. Para los fines limitados de este artículo y por mor de un acuerdo mínimo en cuanto a la terminología, sigue a continuación una versión. abreviada de la misma.

\section{LA DIVISION INTERNA DE LOS SISTEMAS MATEMATICOS}

En el presente contexto, pensemos en los sistemas como formados por componentes, procedimientos y relaciones. De una manera más formal, podríamos pensar en un sistema como en un triple ordenado $(C, P, R)$ consistente en un cojunto de componentes, un conjunto de procedimientos y un conjunto de relaciones.

Los componentes son discernibles, múltiples, pasivos en relación a los pro- cedimientos y sometidos a las relaciones. Son cosas, objetos, elementos, puntos, individuos... a reconocer y manipular. $\mathrm{O}$ se ven, o se pasan por alto.

Los procedimientos son activos y apuntan a lo práctico; exigen tiempo, energía y destreza. Son acciones, transformaciones, procesos, operaciones, algoritmos, rutinas, funciones... a ejecutar. O se hacen, o se omiten.

Las relaciones son más sutiles y apuntan a lo teórico; vinculan o separan las cosas entre sí. Son atracciones o repulsiones, similitudes o diferencias; relacionan, estructuran, organizan componentes. O se captan, o se pierden.

Es instructivo tratar de definir componentes, procedimientos o relaciones. Todas las definiciones acaban siendo circulares. Se han dado algunos intentos de reducir procedimientos a relaciones $y$ relaciones a conjuntos de n-uplos ordenados. Como reducciones útiles, pueden ser prácticas para unos fines determinados; como definiciones, erran completamente el blanco. Puede considerarse que los componentes son las piezas de construcción de los sistemas. Puede considerarse que los procedimientos proporcionan la dinámica a los sistemas. Y puede considerarse que las relaciones proporcionan la estática - la estructura- a los sistemas.

Los sistemas tienen estructura, no al contrario. Varios sistemas pueden tener la misma estructura. Los mismos componentes pueden organizarse en estructuras distintas. Se pueden detectar varias estructuras distintas en el mismo sistema; pero cuando se fija una estructura definida y se olvidan, rechazan o abstraen las demás, se empieza a hablar de un sistema definido únicamente por la estructura en cuestión. Se habla de la estructura de agrupamiento ordenado del sistema de los enteros bajo la adición con el orden usual, y se abstrae de la estructura de anillo o de la estructura parcialmente ordenada determinada por el orden multiplicador (divisor/múltiplo). Aquí, los enteros son los componentes, la adición es el procedimiento y el orden aditivo usual es la relación. Pero se puede tener un conjunto entero de procedimientos como la adición, la sustracción, la multiplicación, la división euclidiana, entre otras; y un conjunto completo de relaciones como estrictamente menor que, menor o igual que, estrictamente mayor que, mayor o igual que, divisor propio, divisor o igual, múltiplo 
propio, múltiplo o igual, antecedente, consecuente, opuesto (en cuanto a signo), entre otros. Todos los procedimientos mencionados son binarios en el sentido de que cada uno trata con dos componentes a un tiempo para producir otros; pero hay muchos procedimientos en los que sólo interviene un componente a la vez (unarios), o tres componentes a la vez (ternarios) o $n$ componentes a la vez (procedimientos $n$-arios). También todas las relaciones mencionadas son binarias en el sentido de que cada una de ellas vincula o no dos componentes a la vez; pero también hay muchas relaciones que vinculan o no un único componente a la vez (predicados unarios), o tres componentes a la vez (ternarios) o $n$ componentes a la vez (relaciones $n$-arias).

Cada procedimiento define una relación asociada natural que vincula los componentes empleados como argumentos y los obtenidos como resultado: la relación entre las materias primas y el producto acabado. Estas relaciones que se obtiene de los procedimientos (pero que son distintas de ellos) junto con las relaciones dadas explícitamente, constituyen la estructura del sistema. Las relaciones estructuran, organizan, sistematizan el sistema. Un sistema sin relaciones $(y$, en consecuencia, sin procedimientos) es un sistema "muerto": carece de estructura. Por tanto, un conjunto de componentes es el cadáver de un sistema. Se pueden definir, o montar o construir muchas estructuras con el mismo conjunto de componentes, que se denomina universo o conjunto subyacente al sistema.

Las estructuras son abstractas en relación a los sistemas. En cierto sentido, las estructuras son lo que tienen en común varios sistemas similares: pueden tener la misma estructura en un sentido que se precisa con facilidad. A su vez, los sistemas, por muy abstractos que puedan parecer, son concretos con respecto a las estructuras. El grupo aditivo de los enteros es un sistema concreto; la estructura del grupo abeliano es abstracta: muchos otros sistemas concretos tiene la misma estructura del grupo abeliano.

Esta manera directa de dividir los sistemas en tres tipos de entidades muy diferentes fue de lo más fructífera en el análisis conceptual de todos los sistemas matemáticos encontrados en el currículo escolar, desde preescolar hasta la uni- versidad. Sin la clarificación conceptual aportada por esta división interna tripartita de los sistemas matemáticos, el análisis cultural hubiera sido imposible 5 .

\section{LA DIVISION EXTERNA DE LOS SISTEMAS MATEMATICOS}

Una vez analizados internamente en componentes, procedimientos y relaciones, puede verse que todos los sistemas de la matemática escolar y todos los sistemas que funcionan culturalmente como matemáticos o protomatemáticos fuera de la escuela existen a tres niveles muy distintos.

\section{Nivel superficial: Sistemas simbólicos}

Son los únicos que aparecen en los libros de texto. No es de extrañar: en los libros de texto sólo se pueden imprimir símbolos. Son los únicos que se enseñan a los niños. No es de extrañar: los maestros sólo pueden emitir sonidos, dibujar signos, formar gestos, $y$ todo esto es, exclusivamente, transmisión de símbolos.

Los filósofos formalistas de la matemática piensan -0 tratan de obligarse a sí mismos a pensar - que los sistemas simbólicos son la totalidad de la matemática. Por fortuna, no es así. Los sistemas formales ni siquiera son la totalidad de los sistemas simbólicos de la matemática: la mayoría de las matemáticas escritas y habladas consisten en sistemas simbólicos informales.

Los sistemas de numeración (a diferencia de los sistemas numéricos) son buenos ejemplos de sistemas simbólicos. Tomemos por ejemplo la numeración romana o nuestro propio sistema decimal arábigo-hindú.

\section{Nivel básico: Sistemas conceptuales}

Una vez asignados al formalismo y al conductismo sus nichos adecuados, las filosofías constructivistas de la matemática y las escuelas cognitivas de la psicología pudieron volver a hablar de construir, manipular y comprender sistemas conceptuales sin sentimientos de culpa. Los sistemas conceptuales son los que se adoptan en los buenos libros de texto, aun cuando sólo puedan hablar o escribir de ellos mediante sistemas simbólicos (ya hay libros de texto parlantes en el mercado). Los sistemas conceptuales son los que construyen los niños con 
lentitud - no siempre con dolor- desde sus primeros meses de vida. Los sistemas numéricos (a diferencia de los sistemas de numeración) son buenos ejemplos de sistemas conceptuales. Tomemos por ejemplo los denominados números naturales o números cardinales con sus procedimientos (operaciones) y relaciones usuales. Evidentemente, los números "naturales" son tan "artificiales", tan obras de arte, tan construidos y elaborados, tan hechos por el hombre o la mujer como cualquier otra cosa que se nos pueda ocurrir. Pero se construyen tan pronto que parecen naturales. También nos podemos dar cuenta de que el sistema conceptual de los números naturales con sus procedimientos y relaciones es independiente del sistema de numeración que elijamos, sea hablado en inglés, sea hablado en castellano, sea escrito en cifras romanas, sea escrito en cifras arábigo-hindús, sea codificado en binario. Es esencial darse cuenta de que un único sistema conceptual en el nivel básico puede aparecer como una pluralidad de sistemas simbólicos en el nivel superficial.

\section{Nivel arcaico: sistemas objeto}

Hubo que cavar mucho para descubrir los diferentes estratos que se hunden en el subsuelo. Piaget, Vygotsky y Bruner contribuyeron mucho a ello. El análisis del lenguaje y las "entrevistas clínicas" aún ayudaron más. Pero se pueden hacer muchos análisis y muchas entrevistas clínicas sin saber lo que se busca. Las ideas clave proceden de un libro desconocido publicado en 1973 por el historiador y filósofo de la matemática de origen francés Pierre Raymond. Es desconocido para los matemáticos y los educadores porque nadie deduciría, a partir de su título (Le passage au matérialisme) que tiene algo que ver con la matemática; y es desconocido para los filósofos materialistas porque cesan de leerlo en cuanto se dan cuenta de que trata de la matemática. Resulta que a mí me gusta la matemática, entre otras ciencias, y también me gusta la filosofía materialista, entre otras filosofías, y encontré el libro fascinante. Indica el camino para una arqueología de las construcciones matemáticas. Muestra que los sistemas conceptuales de reciente construcción en la matemática proceden de la abstracción de transformaciones activas en sistemas más profundos. A continua- ción, estos se olvidan. Por tanto, los sistemas arcaicos son pasivos en relación al sistema activo que actúa sobre ellos. Son concretos en relación al sistema conceptual de reciente construcción, que es abstracto por definición: se abstrae, se extrae del sistema o sistemas concretos que le dan origen. Son naturales con respecto al sistema conceptual artificial construido con ingenio, que sustituye o supera a los sistemas arcaicos ${ }^{6}$.

\section{NIVEL ARCAICO: SISTEMAS OBJETO}

Pensemos en niños jugando con colecciones concretas de objetos cotidianos. Si pensamos en colecciones de dibujos, juguetes, piezas de vajilla o, aún mejor, en colecciones de piedras o de chapas, nos podemos imaginar a un niño de un barrio pobre de Colombia trasladando cosas de acá para allá, observando, sopesando, amontonando cosas, inventando sus propios juegos. Al principio tiene algunos objetos con los que jugar, realiza con ellos algunas acciones y percibe algunas similitudes y diferencias entre ellos. Esto es, precisamente, un sistema con sus componentes, sus procedimientos, sus relaciones. Mediante el agrupamiento de objetos con la mano, mediante la «Gestalten» visual-neural, mediante las propiedades comunes, mediante comparaciones, su sistema original de piedras y chapas se convierte en el sistema objeto de un nuevo sistema de colecciones de estos objetos. Los nuevos objetos son ahora colecciones, subcolecciones de la original (que normalmente no incluyen a la colección original completa ni a la colección vacía). Luego empieza a reunir y desunir colecciones a partir de otras colecciones; agrupa y separa; aparta las chapas de una marca dada de refrescos del resto; coloca una pila o una hilera de chapas encima o al lado de otra. Percibe algunas similitudes y diferencias entre las colecciones. Esto es, precisamente, un nuevo sistema: sus componentes son las subcolecciones; sus procedimientos son la reunión y la complementación; sus relaciones son la inclusión, la disyunción, no tener nada en común con, tener un número mayor de objetos que, tener un número menor de objetos que, tener el mismo número de objetos que...

A medida que el niño juega con el sistema objeto original, empieza a cons- 
truir un sistema conceptual muy interesante, descrito en detalle por Piaget y clasificado por él como "Agrupamiento": casi un grupo, pero no del todo; casi un retículo, pero no del todo. Puede que a los matemáticos no les guste este mounstruo híbrido, pero basta para jugar con chapas con los preescolares del vecindario durante media hora para llegar al convencimiento de que el sistema conceptual que están construyendo no es el álgebra booleana usual de conjuntos con unión, intersección y complementación, ni el retículo booleano de conjuntos con inclusión que los fanáticos de la Matemática Moderna creen que son. Pero tampoco es el sistema de los números naturales. Los fanáticos del Retorno a lo fundamental piensan que están construyendo los dos. Mi hipótesis es que el fallo de la Matemática Moderna se debe a la falta de similitud entre el sistema conceptual de los enseñantes y el de los autores de los libros de texto (el álgebra booleana usual de conjuntos o su retículo equivalente) y el sistema conceptual de los niños: el sistema de juegos de colecciones que tiene, entre otras, una estructura de «agrupamiento". Pero ahora, si nos hemos dado cuenta de las tres relaciones percibidas por el niño en su juego de colecciones, parecen tener que ver algo más con el número: menor que, mayor que, igual. Pero aún no. Mi hipótesis sobre el fracaso del "Retorno a lo fundamental» es que trata de forzar a los niños a tragarse los números mediante rutinas simbólicas (las palabras uno, dos, tres..., también son simbólicas), antes de que acaben de disfrutar con los juegos de colección, más adecuados culturalmente (para su edad y su entorno).

Pronto se dan cuenta de que estas relaciones que pueden expresar (en el nivel simbólico) como "menor que" "mayor que" «lo mismo que" dividen de manera natural las subcolecciones en lotes que tienen el mismo número de chapas. Esta relación de equivalencia se construye a partir de las otras dos relaciones de orden "menor que" y "mayor que» cuando falla el orden. La dependencia de muchas relaciones de equivalencia de las relaciones de orden no se encuentra en los libros de texto de matemáticas. Pero se detecta simplemente como un fallo en el ordenamiento: pidamos a un grupo de niños que se pongan en fila por orden de altura; si vemos que dos niños se empujan durante de- masiado tiempo, es que tienen la misma altura.

Observemos que estas relaciones que hemos expresado en el nivel simbólico como "con menos elementos que» "con más elementos que" y "con el mismo número de elementos que" no dependen del concepto de número. Al contrario: el concepto de número se construye a partir de estas tres relaciones, cuando el juego de las subcolecciones se toma como sistema objeto de un nuevo sistema conceptual: los números naturales a partir de "uno" con «subir de uno en uno" como procedimiento natural y "ser el siguiente de" como relación natural. El procedimiento es unario, no binario como la adición. Peano tenía más razón de la que creía cuando formalizó los números naturales en su primera versión a partir del uno y usando el consecuente como la única operación. A los niños les gusta su sistema.

Pero no les gusta el sistema de números naturales de los maestros y de los libros de texto con sus cuatro operaciones (ninguna de ellas es la que les gusta a ellos) y sus dos relaciones de orden aditivo: menor o igual, mayor o igual. Los niños aceptan más bien las relaciones: estrictamente menor que, estrictamente mayor que. Pero para los matemáticos estas relaciones no son reflexivas y, de ahí que, por la definición de la relación de orden, no deberían denominarse "órdenes». Denominarlas «órdenes estrictos" es una contradicción de términos, a pesar de la amplitud de su uso. Al principio, los niños construyen un sistema numérico conceptual para cada tipo de juego de colección: dos chapas, dos piedras, dos caramelos... La existencia real pero efímera de estos sistemas numéricos concretos es ampliamente testimoniada por la lingüística y la psicología cognitiva. Son etapas intermedias en la construcción del sistema de números naturales, abstractas en relación a los juegos concretos de las subcolecciones "menor", "mayor" o «igual», juegos que a su vez eran abstractos en relación a los juegos con chapas, piedras, dibujos o caramelos.

La aritmética «a la antigua» sigue hablando de "números concretos" como dos chapas y "números abstractos" como el dos. Vale la pena revivir esta distinción. Marca los sistemas protomatemáticos culturalmente relevantes a partir de los cuales se construye el sistema matemático de los números natu- 
rales con sus operaciones y relaciones en el nivel conceptual. Es el que Norma $\mathrm{X}$ sabía manejar.

En cuanto el sistema de números naturales se construye como abstracto y el niño ha jugado con él durante años, contando hacia adelante y hacia atrás, saltándose dos o tres números a la vez, empieza a darse cuenta de que subir de dos en dos o bajar de dos en dos son procedimientos nuevos e interesantes en sí mismos. Ahora empieza a tratar el otrora abstracto sistema de números naturales como sistema objeto; los procedimientos que actuaban en los números naturales haciéndolos aumentar o disminuir empiezan a tener una personalidad propia. Empieza a construir los enteros con signo. Luego ve que el procedimiento natural entre dos enteros con signo es aplicarlos sucesivamente a un número natural. Los nuevos procedimientos y relaciones empiezan a construirse conceptualmente, y un nuevo sistema, abstracto en relación al sistema objeto de los números naturales, empieza a tomar forma. Lo que un matemático denominaría composición de dos operadores es para el niño la adición natural de enteros: si se aumenta en cuatro y luego se disminuye en tres, es lo mismo que aumentar en uno. ¿ Se trata de adición o de composición? Al niño no le podría importar menos: él puede aplicar el nuevo procedimiento a los componentes nuevamente formados de su sistema conceptual. Los enteros son naturales cuando los números naturales se vuelven tan familiares que parecen naturales. Pero en los libros de texto usuales, todo lo que se encuentra acerca de esta construcción culturalmente natural de los enteros con signo es un confuso y complejo juego de palabras con doble sentido de que los enteros son clases de equivalencia o pares ordenados de números naturales. Sólo un trabajo arqueológico muy preciso podría detectar que estas clases de equivalencia son precisamente los cuerpos muertos (grafos) de los enteros con signo vivos y activos como operadores hacia arriba y hacia abajo que a los niños les encanta construir. En realidad, el operador activo +2 aplicado a los números naturales como sistema objeto tiene como grafo el conjunto de pares ordenados $(0,2),(1,3),(2,4), \ldots$, $(n, n+2), \ldots$ Pero usar esto como definición para un niño que puede construir el operador activo por su cuenta es tan inadecuado como definir una hora como el conjunto de pares ordenados (medianoche, 1 de la madrugada), ( 1 de la madrugada, dos de la madrugada), ..., (11 de la mañana, mediodía), (mediodía, 1 de la tarde), ..., (11 de la noche, medianoche). ¿Nos gustaría así? ¿Y qué ocurre con la hora que hay entre la una $\mathrm{y}$ media y las dos y media? Cualquier chaval honrado nos diría que no le gusta definir los enteros como clases de equivalencia. $\mathrm{Y}$ tampoco los podemos listar todos. Sin embargo, realmente podemos construir el concepto en cuanto podemos contar los números naturales hacia arriba y hacia abajo de uno en uno o a saltos. Y se trata de procedimientos difíciles de dominar. Los fanáticos del Retorno a lo fundamental tienen razón en insistir a los fanáticos de la Matemática Moderna que no deberían enseñar los enteros como clases de equivalencia; pero se equivocan al tratar de forzar a los niños a dominar los enteros mediante rutinas simbólicas que serán olvidadas y confundidas justo después del examen final si no están articuladas con los procedimientos de salto hacia arriba $y$ hacia abajo.

Por cierto, la infinidad de números naturales y de enteros positivos (como operadores no son lo mismo que sus objetos) es fácilmente comprensible por los niños pequeños como lo ilimitado (la infinitud) en cuanto dominan el procedimiento de aumentar. Permítaseme acabar esta sección con la siguiente historia verídica.

En 1978, Santiago Z, en aquellos tiempos un estudiante de segundo curso, empezó una competición conmigo: él decía un número grande y yo le debía contestar con otro mayor, etc. Empezó sin problemas: « Noventa!». Yo dije: «Ciento noventa!». « $i$ Doscientos!» dijo él. «iDos mil!" dije yo. « Noventa mil!" continuó él, a lo que yo respondí: "iCien mil!». Se exasperó y chilló: « ¡Infinitos mil!». Perdí yo.

\section{NIVEL BASICO: SISTEMAS CONCEPTUALES}

A estas alturas deberá quedar claro que el nivel básico se desplaza hacia arriba en cuanto se domina un sistema y puede convertirse en el sistema objeto de la siguiente construcción. Cabe reconocer a Piaget el mérito de darse cuenta de que la nueva construcción es el resultado de una «abstracción reflexionante» 
de procedimientos, no de objetos ni de relaciones. Los procedimientos adquieren el status de objetos cuando se olvida el sistema arcaico. Esto ocurre con los enteros con signo y con los números racionales, que surgen culturalmente como procedimientos en sistemas objeto y que después se convierten en objetos pasivos que se pueden representar como puntos en una linea estática. Los enseñantes y los autores de libros de texto piensan que estos son los enteros o las fracciones, y confunden los temas sin esperanza para los pequeños que tratan de construir los procedimientos activos y dominarlos. El primer sistema conceptual que era matemático con respecto al sistema objeto protomatemático de las chapas era el "agrupamiento" o subcolecciones de chapas. A partir de muchos juegos de colecciones de este tipo surge un segundo sistema conceptual, el de los números naturales a partir del uno, que tiene, como procedimiento natural, pasar al número siguiente. A partir de este sistema conceptual inicial puede construirse el sistema completo de los números naturales con muchas operaciones y relaciones en el nivel conceptual. Los sistemas conceptuales originales de subcolecciones se superan, se olvidan. Los procedimientos de ir hacia arriba o ir hacia abajo a saltos dan pie a un nuevo sistema conceptual de enteros con signo con procedimientos y relaciones culturalmente naturales. Una vez construido este sistema básico, se puede ampliar introduciendo nuevos procedimientos y percibiendo nuevas relaciones. Entonces, este nuevo sistema conceptual toma vida propia y nadie se vuelve a dar cuenta de sus raíces arcaicas. Las "víctimas" de los procedimientos hacia arriba y hacia abajo, es decir, los sistemas objeto, están enterrados profundamente, y el sistema conceptual de los enteros con signo con sus operaciones y relaciones usuales está presto para convertirse en el sistema objeto de un nuevo sistema conceptual; las funciones con valores enteros de los enteros con signo tan queridos de los teóricos del número.

Para apartar la atención de los sistemas simbólicos he tratado de evitar cualquier símbolo matemático en el texto precedente. Para recalcar el aspecto que trato de destacar, debo decir que las palabras que he empleado para describir los sistemas objeto y los sistemas conceptuales no son realmente los objetos, procedimientos o relaciones: se refieren simplemente a ellos; pero con el empleo del lenguaje cotidiano pretendía transmitir el concepto de sistemas arcaicos y básicos como algo diferente de los sistemas simbólicos. Sintiéndolo mucho, no me es posible imprimir aquí un sistema objeto o un sistema conceptual; sólo puedo ofrecer algunas pistas sobre la manera de construir un sistema conceptual cuando se ha identificado un sistema objeto familiar. Quisiera ahorrar al lector el trabajo de construcción (¿telepatía directa, quizá?). Pero así, también se podría perder toda la diversión.

\section{NIVEL SUPERFICIAL: SISTEMAS SIMBOLICOS}

Ahora, cuando llegamos a los sistemas simbólicos, idear un sistema simbólico cuando se domina el sistema conceptual es un juego de niños. Tratemos de disenar un sistema simbólico para el sistema más primitivo de las chapas. $\mathrm{O}$ para el sistema de los juegos de colección. O un sistema para los números naturales, o para los enteros, o para los números racionales que sea diferente de los sistemas de numeración corrientes y molientes. Nuestro diseño podría no ser muy bueno para ciertas cosas como sumar o multiplicar números grandes; pero podría ser muy bueno para otras. Una simple cuenta de barras espaciadas con regularidad es muy adecuada para el sistema conceptual recientemente formado de los números naturales acabado de extraer de los sistemas objeto de los juegos de colecciones. No hace falta un símbolo para la operación natural de "pasar al siguiente»: basta con escribir una barra más a la derecha. Y si se va con cuidado, las relaciones de orden se comprueban fácilmente comparando longitudes:

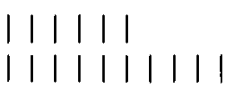

Si nos cansamos de contar las barras una por una, probemos el truco usual de tachar los cincos con la barra de los cincos: \#廿 es un símbolo muy adecuado para el número cinco.

Distintas culturas han desarrollado sistemas simbólicos diferentes para el mismo sistema conceptual de los números naturales. ¿Cómo sabemos que es el mismo? Naturalmente, la «identidad» del sistema conceptual sólo puede infe- 
rirse a partir de coincidencias, facilidad de traducción, éxito en las práticas comerciales u otros síntomas observables. Es evidente que en el nivel básico se alcanza un elevado nivel de universalidad. ¿Pero es sólo en el nivel simbólico donde se sitúa la diversidad cultural? Mi respuesta es un «iNo!» categórico. La diversidad cultural también se encuentra en el nivel arcaico de los sistemas objeto, y esta localización es más importantes y mucho más profunda que la diversidad superficial de los sistemas simbólicos.

\section{CONSECUENCIAS PEDAGOGICAS}

La primera idea general es que el enseñante, el diseñador de currículos y el investigador deberán tratar de empezar desde el fondo: explorando la diversidad de sistemas objeto culturalmente concretos que dan origen a un sistema conceptual.

En el presente marco teórico, no pueden enseñarse realmente las matemáticas en el nivel conceptual. Se puede conformar el entorno adecuado y dar las pistas correctas para fomentar el juego significativo con los sistemas objeto culturalmente familiares para ayudar a los niños a construir el sistema conceptual; cuando ya lo han construido, se les deberá estimular para que inventen sus propios sistemas simbólicos. Habrá una pluralidad de sistemas objeto que puedan dar lugar al mismo sistema conceptual; la elección de aquellos con los que se estimulará a jugar a los niños para que los dominen debe hacerse en función de su familiaridad y su utilidad cultural; pero si un niño, o mejor aún, un grupo de niños, desarrolla su propio sistema, se le deberá estimular a que juegue con él y a que lo compare con los sistemas de más difusión cultural. Si comprende el sistema conceptual, hará la traducción con toda facilidad; si no lo comprende, ni siquiera sabrá que es una traducción.

Una segunda idea general es la contrapartida de la primera: afirma que empezar desde los sistemas simbólicos hacia abajo es contraproducente. El dominio mecánico de rutinas simbólicas bloquea el proceso de construcción de conceptos. Los símbolos pueden y deben emplearse para contribuir a la construcción conceptual sobre la marcha, y puede aducirse que el concepto no se puede desarrollar plenamente sin alguna forma de simbolismo que lo acompañe. Pero las prioridades deberían estar claras.

Cuando los niños conocen algunos símbolos, pueden ir profundizando hacia los posibles conceptos subyacentes y los sistemas objeto que les subyacen con toda seguridad. Si avanzan desde los sistemas objeto hasta algunos conceptos, se pueden empezar a buscar símbolos. Se deberían fomentar estas subidas y bajadas, pero destacando que la tendencia principal debe ser ascendente a partir de distintos sistemas objeto que posean la misma estructura. Una vez se haya construido parcialmente el sistema conceptual y se le haya adjuntado un sistema simbólico determinado, podemos probar distintos sistemas simbólicos que tengan el mismo significado. Tratemos de inferir si el significado se encuentra realmente ahí: bajemos hacia distintos sistemas objeto para ver si los conceptos se les pueden aplicar correctamente. Luego subamos por la escalera otra vez.

En el libro antes mencionado [Apartado V.III], Pierre Raymond muestra cómo se repite, en toda la historia de la matemática, esta simple pauta de usar uno o más sistemas objeto como materia prima concreta para la construcción de sistemas conceptuales abstractos. $\mathrm{Mi}$ propuesta es dejar que la «ontogénesis» o reconstrucción de estos sistemas por parte de los niños, siga al menos alguna de las pautas de la "filogénesis" o construcción de estos sistemas en la historia de la matemática.

Pero no estoy recalcando el tópico usual (y erróneo) de enseñar las matemáticas únicamente a través de los denominados métodos concretos o materiales concretos. Raymond observaba la relatividad antes mencionada de la clasificación de un sistema determinado como concreto o abstracto también en el nivel histórico. Piaget la observaba en el nivel genético. Pero la pauta es la misma: en cuanto se desarrolla un buen sistema simbólico para el sistema activo y se alcanza un nivel suficiente de familiaridad, un nuevo sistema activo utiliza el sistema anterior como sistema objeto y el nuevo sistema conceptual puede tener tanto éxito que ahora se convierte en concreto y el primer sistema concreto desaparece en el trasfondo y se olvida con rapidez.

Estoy abogando por una operación de rescate para recuperar estos sistemas concretos donde se encontrará que resi- 
de la dependencia cultural original. Puede que, a su vez, demuestren ser muy relativos, pero esto no importa. Ciertamente, la palabra «concreto" es muy relativa.

Piaget ha criticado con agudeza la confusión entre estas actividades en la escuela y los métodos verdaderamente activos. Cualquier percepción, cualquier palabra significativa de un niño de tres años ya es abstracta: vincula entre sí muchos objetos y olvida, o abstrae, muchas diferencias que podrían ser importantes. Para esta construcción hace falta una gran actividad mental. Es esta actividad en los sistemas que son concretos en cada momento lo que debe recalcarse.

Vygotsky observó también que los métodos de enseñanza empleados con los niños mentalmente atrasados, basados en técnicas concretas de «mirar y hacer" habían acabado en una profunda desilusión:

Resulta que los sistemas de enseñanza basados únicamente en lo concreto -los sistemas que eliminan de la enseñanza todo lo asociado con el pensamiento abstracto- no sólo fracasan en ayudar a los nin̄os atrasados a superar sus dificultades innatas sino que también las refuerzan al acostumbrar a los niños a un pensamiento exclusivamente concreto. Ahora se ve que lo concreto sólo es necesario e inevitable como trampolín para el desarrollo del pensamiento abstracto, es decir, como un medio y no como un fin en sí mismo ${ }^{6}$.

Las ideas anteriores forzaron un replanteamiento a fondo de todos los sistemas impartidos en los niveles de primera y segunda enseñanza, desde los números naturales con sus operaciones y relaciones usuales hasta las funciones reales del cálculo elemental con sus operaciones y relaciones. Se encontraron muchas sorpresas en todos los niveles, desde las colecciones más concretas de objetos familiares que emplean los niños como sistemas objeto para construir sus números para contar, hasta el comportamiento extravagante de las funciones $y$ las derivadas.

Un informe completo de las investigaciones realizadas en todos estos sistemas será el tema de un próximo libro. Muchos aspectos de esta investigación podrían denominarse culturales, antropológicos, lingüísticos, psicológicos o matemáticos. Pero la pauta general se repetía una y otra vez. Detalles aparentemente triviales de lenguaje, problemas de aprendizaje, posibles errores, reac- ciones negativas de los nin̄os, condujeron al descubrimiento de los sistemas culturales relevantes, destacando el sistema conceptual y relacionando los distintos sistemas simbólicos adjuntos a él. En los apartados siguientes se presentan algunos ejemplos breves.

No se discute la representatividad ni la generalización de estos ejemplos. Sería difícil separar lo que es específico de un niño determinado, de una subcultura determinada o de un país determinado, de lo que es general o universal, o destacar lo que se debe a factores culturales, o a factores genéticos o a una interacción de los dos. Es evidente, por ejemplo, que los objetos peculiares o los juguetes locales con los que juegan los niños no son los mismos en culturas distintas; ni siquiera son los mismos en distintos estratos de la población de la misma ciudad de Bogotá. Pero, ¿ por qué los juegos de los niños han resultado ser más universales de lo imaginado? ¿Por qué los psicólogos del desarrollo determinan pautas sorprendentes similares en el crecimiento de los niños de Ginebra, de París, de Nueva York o de Yakarta? La hipótesis que subyace a la presentación de ejemplos procedentes de mi experiencia limitada es que se encontrará que los esquemas de acción de los niños son muy similares en culturas distintas, independientemente de lo diferentes que puedan ser los objetos de estas acciones o las etiquetas lingüísticas que se les asigne.

Si la matemática surge de la articulación de estos esquemas de acción, como afirma Piaget, y no de las reacciones de los objetos ni de la repetición de símbolos escritos o hablados, la pauta para una pedagogía correcta de las matemáticas que sigue a continuación puede transferirse a culturas y entornos completamente distintos: explorar en primer lugar las actividades matemáticas y protomatemáticas de la cultura local; recoger el lenguaje que empleen los niños y los adultos para representar los objetos, los procedimientos y las relaciones correspondientes; partir de los sistemas objeto concretos encontrados en esa cultura y emplear el lenguaje local para provocar estos esquemas de acción o pautas de actividad en los sistemas objeto. Observar los síntomas de la construcción real de sistemas conceptuales y dejar que varios sistemas simbólicos fluyan o se adjunten a estos sistemas conceptuales. Es mi opinión que esta pauta de actividad 
educativa se puede generalizar a la enseñanza y el aprendizaje de las matemáticas en otras culturas.

\section{TEORIA DE CONJUNTOS}

La teoría de conjuntos, tal como era transmitida por los libros de texto de la Matemática Moderna, resultó ser muy ajena a nuestro entorno cultural. Naturalmente, los enseñantes británicos y holandeses lo descubrieron muy pronto después de la introducción de la Matemática Moderna en sus propios marcos culturales, y los enseñantes japoneses la rechazaron al cabo de unos cuantos meses.

Sin embargo, al profundizar un poco se encontraron estratos más profundos que eran manejados alegremente y con facilidad por los niños colombianos. Muchas situaciones culturalmente familiares que daban pie a los números para contar resultaron ser naturales e interesantes para los niños. Las denomino "juegos de colecciones». Los niños identifican, emplean, cuentan, etiquetan, reúnen y separan colecciones de objetos cotidianos dentro y fuera de la escuela, con toda facilidad: sus canicas, sus juguetes, sus utensilios escolares, muebles, cubiertos y vajilla, sellos de correos, cromos, etc.

La clave teórica era la distinción de Piaget entre colecciones (tanto figurativas como no figurativas) y clases operacionales. Las colecciones figurativas concretas deben ser visibles como una «Gestalt» simultánea y deben tener un mínimo de dos elementos. Las colecciones no figurativas concretas también deben contar, al menos, con dos elementos, y todos los miembros de la colección deben tener una propiedad común $y$ recibir la misma etiqueta. No hay colecciones vacías ni colecciones de un sólo elemento. Estas colecciones no son conjuntos matemáticos: son sistemas con muchas relaciones internas y operaciones y procedimientos activos. Los niños nunca perciben a los miembros de su familia y a sus compañeros de clase como conjuntos de elementos sueltos, desordenados, no estructurados. El conjunto con sus elementos muertos, sus procedimientos congelados y sus relaciones difuntas no es más que el cadáver del sistema. No es de extrañar que a los niños no les gusten los conjuntos; pero les encantan los sistemas. ¿En qué lugar del mundo hay un niño que acepte que el conjunto $[a, b, c]$ es lo mismo que el conjunto $[c, a, b]$ ? Esta igualdad sólo es posible a un nivel elevado de abstracción, cuando se ha borrado cualquier señal de estructura en los sistemas originales y se ha arrojado a las oscuras profundidades de la categoría de los conjuntos.

No pretendo negar que puede ser interesante, y hasta necesario, estudiar cadáveres de sistemas más adelante. En biología también es necesario diseccionar ranas muertas y matar células con tintes para verlas por el microspocio. Sólo digo que los niños prefieren realmente las ranas vivas y las células que se mueven. También prefieren los sistemas vivos, ligados y estructurados a los conjuntos muertos, sueltos y no estructurados. Si las palabras «conjunto» y «elemento" no se fuerzan al niño y nos abstenemos de los conjuntos vacíos y unitarios, el niño se siente con plena libertad en esta parte de la teoría de conjuntos que refleja juegos concretos de colecciones. Cabe recordar que, para los griegos, y hasta la aritmética del Renacimiento, el cero y el uno no eran números: los números empezaban con el dos. Todavía seguimos estando de acuerdo con nuestros antecesores en que la unidad no es ni prima ni compuesta; pero nos resistimos ante la afirmación perfectamente paralela de que la unidad no es par ni impar. Pero ellos aceptaban las dos, simplemente porque la unidad no era un número.

Se encontró que los procedimientos culturalmente naturales con colecciones eran la unión y la complementación. Los niños rechazaban emplear la conjunción «0» en la unión de colecciones, tal como prescriben todos los libros de texto sobre la teoría de conjuntos: prefieren la conjunción " $y$ » que, según los libros de texto, debe emplearse para la intersección de conjuntos. Pero los niños insisten en decir "Los bloques azules y los discos" para la unión, y no empleen ninguna conjunción para la intersección: "Los discos azules". Los niños tenían razón. Tanto peor para los libros de texto.

Estas sencillas exploraciones del mundo cultural de los juegos de colecciones de los niños, llevada a cabo con el estado de ánimo de un antropólogo cultural con formación matemática, me permitieron reescribir gran parte del material de la Matemática Moderna que los 
maestros solían repetir sin mucha comprensión y los niños solían repetir sin ninguna. Se recuperaron muchas de las virtudes de la versión adecuada de la teoría de conjuntos, y en sus raíces se detectaron muchos errores bien conocidos.

\section{LOGICA}

Otra sorpresa fue el contraste entre la «Lógica de la Matemática Moderna» que ahora se enseña en muchos centros de primera enseñanza y los juegos de lenguaje lógico específicos de la cultura en que juegan los niños. Resultó que los niños pequeños no comprenden la lógica de proposiciones ya que los libros de texto parten del supuesto de que los ninos suelen tener una idea pura de premio-castigo respecto a decir la verdad. Pero una versión adecuada de la denominada lógica deóntica de algunos lógicos díscolos resultó ser perfectamente comprendida por los niños pequeños de una manera muy precisa: constantemente se les dan instrucciones, órdenes, prohibiciones, promesas de premios y castigos condicionados. Pero en este marco culturalmente sintonizado, las tautologías usuales dejan de ser válidas. La conjunción «y» no es conmutativa; tratemos de conmutar: «Quítate los zapatos y sácate los calcetines". A causa de la dependencia temporal de las condiciones, la afirmación contrarrecíproca no es equivalente a la expresión original y «Si $p$, entonces q» es interpretada por los niños como "O p o no q"; los libros de texto nos aseguran que esta transformación es incorrecta y que la correcta es "O no $\mathrm{p}$ o q" que los niños se niegan a aceptar. En realidad, los niños siempre interpretan $« \mathrm{Si}$ te portas bien podrás ir al cine" como " $\mathrm{O}$ te portas bien, o no podrás ir al cine» y nunca como "O no te portas bien, o podrás ir al cine» que es ridícula. De nuevo los niños tienen razón y los libros de texto, no. De nuevo vuelvo a decir: tanto peor para los libros de texto?

\section{NUMEROS NATURALES}

Los números naturales se asocian a sistemas concretos de juegos de colecciones con etiquetas numéricas adjuntadas como cuasi-adjetivos a nombres plurales, o con listas numéricas aprendidas de memoria adjuntadas a objetos de una colección concreta señalando con los dedos. Los dados, las fichas de dominó o los juegos de cartas pueden ser muy conocidos por los niños pequeños que pueden determinar las pautas como "Gestalten" sin necesidad de contar puntos o bastos. Las palabras que emplean pueden colisionar con el sistema numérico decimal; por ejemplo, «diez» es una palabra más corta que "nueve» pero "10" tiene más símbolos que "9". Los números 11 y 12, cuando se leen en voz alta, no tienen nada que ver con los símbolos; en castellano, los números 11 a 15 no se leen «diez y uno, diez y dos, ... diez y cinco" como debería ser. Pero no tenemos el problema que tienen los alemanes: 21 se lee al revés como «einundzwanzig»; compáreselo con el «undeviginti» latín, que equivale a nuestro 19. Y no hablemos ya del problema francés con el "quatre-vingt-dix-neuf»...

Para mencionar sólo una operación, un estudio de la división guiado por unas pocas pistas dadas por la matemática italiana Emma Castelnuovo, llevó a la detección de dos tipos distintos de procesos de división culturalmente familiares, ninguno de los cuales coincidía con el impartido en la escuela:

I. Dar el mismo número de elementos de un lote dado de caramelos a cada uno de los niños de un grupo dado. El resultado es un número de elementos.

II. Partir una cantidad dada de elementos en lotes de un tamaño dado, dando cada lote a un niño. El resultado es un número de niños.

Los niños colombianos habla del primer proceso como de «repartir caramelos entre niños". Para el segundo proceso emplean la expresión "Repartir de a». Pero ambos procesos pueden realizarse sin emplear la multiplicación y, por tanto, no coinciden con el proceso de división impartido en la escuela ni con las palabras empleadas en los libros de texto: "Dividir por". La independencia de los procesos culturalmente familiares para la división respecto a la multiplicación se observa fácilmente fuera de la escuela, a pesar de la identificación que hacen los libros de texto de la división como la operación inversa a la multiplicación. Un matemático francés me dijo que hay grupos nativos que practican la adición, la sustracción y la división, pero no saben multiplicar. Si esto se confirma, su existencia apoyaría en el ámbito 
filogenético la independencia ontogenética observada entre la división y la multiplicación.

\section{ENTEROS}

Se encontró que los niños rechazaban instintivamente los enteros negativos. Este concepto se ha conocido durante siglos pero no tuvo una acogida fácil en las matemáticas. El maestro del álgebra renacentista, Cardano, tildaba a las soluciones negativas de las ecuaciones de segundo y tercer grado de "ficticias", «inútiles» e incluso "falsas" ${ }^{8}$. Nunca quedamos del todo convencidos que menos por menos dé más; decidimos aprenderlo de memoria como una regla rutinaria, sin tratar de entenderla.

Pero los niños pueden construir los enteros positivos y negativos como operadores conceptuales activos que hacen cambiar las cosas de un sitio a otro: los números naturales al contar, las calles a lo largo de una avenida, los escalones de una escalera y otras cosas más familiares para ellos que las deudas o las temperaturas bajo cero. Los enteros son operadores activos que cambian las cosas hacia arriba $n$ pasos $(+n)$ o hacia bajo $n$ pasos $(-n)$. El operador de identidad no mueve las cosas nada (0). Pero el proceso natural entre dos de estos operadores activos no es la adición: es la aplicación sucesiva (o composición) de los dos operadores: ya hemos destacado anteriormente que subir cuatro $(+4)$ y luego bajar tres $(-3)$ es lo mismo que subir uno $(+1)$, es decir: +4 ó $-3=+1$, donde el círculo pequeño representa la composición de operadores, que no es más que una manera estrafalaria y culturalmente ajena de decir que aplicamos uno después del otro.

Desde este punto de vista puede observarse que las deudas o las temperaturas bajo cero no son modelos correctos de los enteros negativos. Son más bien dos sistemas objeto más para los operadores culturalmente familiares que actúan en los números naturales al contar, en los escalones de una escalera o en las calles que hay a lo largo de una avenida. En realidad, caminar $n$ manzanas al norte o al sur cambia la numeración de las calles laterales que van en dirección este-oeste de una manera definida: caminar cuatro manzanas hacia el norte $y$ luego tres hacia el sur es lo mismo que caminar una manzana hacia el norte.
Pero no he dicho en qué calle nos encontramos. El sistema objeto es una cosa y el sistema conceptual activo es otra.

La dependencia cultural del sistema objeto quedó patente en un ensayo experimental de este sistema en una escuela de un barrio pobre de Bogotá. En esta ciudad, el norte es un suburbio elegante mientras que los pobres viven en la zona sur. En este sistema, el sistema simbólico evidente para los enteros es $4 \mathrm{~N}, 3 \mathrm{~S}$, $1 \mathrm{~N}$, etc. Identificar 4 y $4 \mathrm{~N}$ quitando la "N" y escribir 4S para el menos cuatro parecía un insulto a los niños del barrio pobre: "¿Por qué se da por sentado que "4" significa "4 hacia el norte"?" " $巳$ Por qué los números del norte se llaman positivos?" "QQué hay de negativo en vivir en la zona sur?» Los niños tenían razón y tuvimos que cambiar el sistema de este a oeste porque hay muy pocas avenidas más al este de la Primera Avenida y nadie se sentiría insultado.

Por último, para estos operadores hay un operador natural de cambio de orientación que se llama «menos» y se escribre «-». Es evidente que si se cambia de orentación dos veces todo se queda como estaba. No hay una «regla de los signos" rutinaria: sólo una comprensión directa de lo que ocurre si se cambia dos veces de orientación. Pero obsérvese que el operador "menos» es ahora un monstruo activo que devora enteros. Las funciones empiezan a aparecer como operadores activos que actúan sobre los ahora familiares enteros, que a su vez se van a fundir en un sistema objeto. El «menos» es un monstruo unario que se come enteros y los devuelve invertidos. Si nos muerde dos veces, acabamos ilesos. Algunos niños del Estado de Antioquía recordaban haber oído a sus abuelos contar esta historia de brujas: si cortamos una bruja una vez con un cuchillo, volverá a nosotros otra vez para hacerse otro corte y curar la primera herida con la segunda. ¿Pensamos que estos niños de Antioquía llegarán nunca a olvidar lo que ocurre si se aplica «menos" dos veces?

\section{FRACCIONES}

Este sistema es el dolor de cabeza de todos los enseñantes de matemáticas. Los estudiantes recién llegados a la facultad parecen haberlo olvidado todo respecto a las fracciones como sabe bien cualquier profesor que haya corregido 
pruebas de derivadas de potencias fraccionales o de integración de funciones racionales. El remedio propuesto por el movimiento del Retorno a lo fundamental es practicar mucho más las fracciones. Se ha intentado, pero la cantidad de ejercicios de repetición parece influir poco o nada en las dificultades con las fracciones que se presentarán en años posteriores; en lo que se sabe que influyen estos ejercicios es en la actitud hacia las matemáticas: hay más niños que odian las matemáticas y hay más adultos que temen las fracciones.

Empecé a pensar que las fracciones eran demasiado difíciles para los estudiantes de tercer curso. Mientras ponderaba la decisión de pasarlas a quinto curso, vi a un grupo de niños de primer curso en una clase de gimnasia que seguían sin problemas una serie de instrucciones sobre medias vueltas y cuartos de vuelta. ¿Habría un sistema objeto culturalmente favorable para las fracciones?

Los niños muy pequeños saben mucho de galones, medios galones, cuartos, pintas y medias pintas siempre y cuando se trate de leche. Luis Eduardo Y y sus colegas mecánicos sabían mucho sobre fracciones de pulgada. Las niñas saben mucho de longitudes fraccionales, siempre que se trate de hilos o cintas. En los países adheridos al sistema métrico decimal las longitudes fraccionales aún son más fáciles de manejar: no hay saltos de doce a un pie, de tres a una yarda o de Dios sabe cuántos a una vara o una milla. Pero el mismo niño que sabe cuánto es cuando vertemos medio galón de leche en un recipiente, y luego un cuarto de galón más, se quedará totalmente perplejo ante el jeroglífico $\ll 1 / 2+1 / 4 »$. ¿Deberá sumar? ¿Multiplicar? ¿Multiplicar en cruz? ¿Hallar el mínimo común denominador? Debemos haber saltado con demasiada rapidez al sistema simbólico sin una construcción previa del sistema conceptual pertinente.

«Fracción» es una palabra ambigua: se refiere a los números racionales y a los símbolos fraccionales. ¿Es lo mismo 1/2 que $2 / 4$ ? iEs evidente que no! $\mathrm{El}$ primer numerador es impar; el segundo es par. Sin embargo, de alguna manera se supone que son lo mismo. ¿Lo mismo que qué? Bien, si el niño no ha construido el número racional conceptual correcto, la cuestión no puede resolverse en el nivel simbólico. Pero en el nivel conceptual, los números racionales no tienen numeradores ni denominadores. Son monstruos activos. Cuando se conoce al monstruo de las mitades, no importa que el maestro escriba $1 / 2,2 / 4,0,50$ incluso $50 \%$. Todo es lo mismo. Pero ahora ya sabemos en qué son lo mismo: no son más que graciosos disfraces para el mismo monstruo de las mitades.

Para los niños de seis a doce años de edad (al menos) es muy importante saber qué se supone que comen los monstruos. Se comen turnos, se comen trozos de cuerda, se comen ciertos números naturales como decenas de docenas. Hasta se comen cantidades de leche o áreas de superficies de cemento. He estudiado todos estos sistemas objeto y es evidente que el más difícil es el de las áreas. Pero es el más fácil de dibujar en la pizarra y en los libros de texto y es, con mucho, el más común; sin embargo, al menos en Colombia, es un sistema objeto culturalmente equivocado desde el que empezar.

También es evidente que las palabras usuales para transformar fracciones, "reducir", "simplificar» y "aumentar" son culturalmente confusas; se dice que simplificar una fracción es lo mismo que reducirla y que lo contrario es aumentarla. Pero los niños asocian una reducción con una disminución de tamaño y un aumento con un crecimiento. Por tanto, propongo emplear "simplificar" y "complicar" que significan simplemente hacer las cosas más sencillas o más complicadas en el nivel puramente simbólico. En el nivel conceptual, los monstruos racionales realmente amplian y reducen lo que se comen (a excepción, naturalmente, del monstruo domado que no causa daño a sus víctimas y que es el «Número Uno»). Es importante tener presente que estos monstruos no se comen tartas ni hojas de papel, como muchos enseñantes parecen pensar. Se comen la masa o volumen de la tarta o el área de la hoja. Las "medias tartas" se identifican fácilmente como un camelo: si me dejas comer mi media tarta, escogeré la mitad superior porque toda la nata está ahí. O si me dejas elegir mi media naranja, escojeré la mitad de dentro y te dejaré la piel. Si preguntamos a un niño qué tendremos si partimos una hoja de papel por la mitad no responderá: "Dos medias hojas" (a menos que sepa que ésta es la respuesta que deseamos oír). Responderá: «Dos hojas pequeñas de papel» y con toda la razón. El monstruo de las mitades no se come los objetos mismos: sólo sus áreas, lon- 
gitudes, masas, pesos o volúmenes.

De nuevo, el procedimiento natural a aplicar a dos monstruos en el nivel conceptual no es la adición: vuelve a ser la composición $o$, mejor aún, la aplicación de uno después del otro. Los niños aprenden enseguida que la mitad de medio galón es un cuarto; que la mitad de media pulgada es un cuarto de pulgada, etc. Pero cuando ven algo como «(1/2) $\times(1 / 2) "$ no saben qué es. ¿Por qué el signo de multiplicar? ¿Por qué decir "por» o «veces» cuando basta con un simple «de»? Cuando los niños se aburren con los sistemas objeto porque ya han construido los monstruos racionales, dicen simplemente: «la mitad de la mitad es un cuarto". Si se les pregunta por los sistemas objeto, se encogen de hombros y dicen: "Es lo mismo». Cuando un niño dice "Es lo mismo" es que ha construido un sistema conceptual: ha aprendido matemáticas.

\section{GEOMETRIA}

Los sistemas geométricos también están repletos de sorpresas. Debo empezar por confesar que la manera que tiene la Matemática Moderna de afirmar que los segmentos de línea son conjuntos de puntos me solía dejar frío o, peor aún, helado. Hay demasiados conjuntos de puntos que no son líneas y el tono dogmático de infalibilidad asumido por el enseñante que repite la afirmación es simplemente exasperante. Cuando un día vi a un niño mirando un segmento de línea con una lupa para tratar de ver los puntos, ya tuve bastante geometría de la Matemática Moderna.

¿Por qué no limitarse a jugar con segmentos de línea como elementos primitivos en un sistema encantador en el que los puntos sean algo desconocido? Al replantear sistemas de segmentos, era evidente que había muchas operaciones o procedimientos interesantes que realizar con ellos: deslizarlos, girarlos, alinearlos extremo con extremo, doblarlos, biseccionarlos y lo que sea. También puede encontrarse una multitud de relaciones: paralelismo, incidencia, congruencia, perpendicularidad.

Empecé a jugar a juegos de segmentos con los niños. Los niños de los barrios pobres encontraban difícil la palabra «segmento"; decían "semento" que suena exactamente igual que "cemento». Por tanto, decidimos llamarlos simplemente "rayitas". Los juegos de rayitas eran sencillos pero activos; los niños estaban deseosos de colocar los palos que representaban segmentos o rayitas por todas partes, girándolos, uniéndolos, deslizándolos. Las preguntas sobre las relaciones los paraba en seco. Casi se podían ver sus neuronas disparando hipótesis; normalmente, no se emitían palabras; quizá un rápido deslizamiento del palo de un pirulí, o una comprobación de longitudes con pulgar e índice como calibrador. Se podía ver el brillo de los ojos en el instante de una intuición. Y una sonrisa. Toda mi formación filosófica empezó a borbotear en mi pensamiento: ¿Es ésta la relación, tanto tiempo ha perdida, entre teoría y práctica?

Ciertamente, los procedimientos y las operaciones reflejan la práctica; las relaciones reflejan la teoría. Los procedimientos son activos; tienen una prioridad en la práctica (se ha de hacer algo para ejecutarlos) y también tienen una prioridad en la teoría (se debe hacer algo para comprobar una relación).

La prioridad de la acción está bien documentada por Piaget. Define las operaciones como acciones interiorizadas, reversibles y coordinadas. Vygotsky habla de la «reconstrucción interna de una operación externa».

Por tanto, aprender es la realización de acciones, operaciones, procedimientos y algoritmos (en el nivel simbólico, los procedimientos se llaman algoritmos). Por tanto, enseñar es facilitar esta realización. Estas observaciones nos ayudan a apreciar las funciones como transformaciones activas, no como relaciones $\mathrm{y}$, mucho menos, como conjuntos de pares ordenados. Y nos ayudan a redescubrir la geometría activa.

Una vez dibujé un segmento de recta hacia abajo y luego la etiqueté de A a B empezando por el punto más cercano a la tiza:
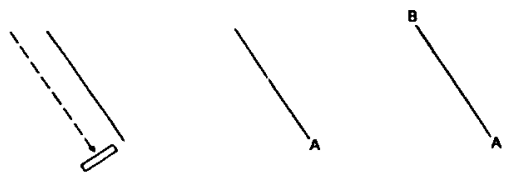

Dije: «Digamos que esta es la rayita $A B$ ». Uno de los niños protestó: «jLa has dibujado hacia abajo! ¿No debería ser la rayita BA?». Me pilló desprevenido. Nos olvidamos de la acción, del mo- 
vimiento; los niños no. Para nosotros, un segmento es un segmento muerto, frío, congelado. Nos es igual que se llame AB o BA. Para los niños todavía está vivo, caliente, dirigido hacia abajo. Traté de imaginar cuántos enseñantes han respondido a la misma pregunta con cara seria y tono dogmático: «Es lo mismo. Y punto." ¿Lo mismo que qué? ¿Para quién es lo mismo?

El mismo grupo de niños que en la clase de gimnasia seguía instrucciones como “¡Media vuelta a la derecha!” y que me condujo al más primitivo sistema objeto para las fracciones, resolvió también el problema de los ángulos. Ahí estaba, el otrora activo ángulo de giro, justo en primer curso. Como la geometría de los niños es dinámica, el concepto correcto de ángulo no es el par de medias líneas (radios) unidas por un extremo. Es la amplitud de un giro, y desde el mismo principio tiene una orientación definida, un interior y un exterior. Pero el ángulo que se dibuja en la pizarra ya está muerto. Ha perdido la orientación, el interior y el exterior.

En 1978 empezé a rediseñar los programas de geometría desde primer a noveno curso reconstruyendo una serie completa de sistemas geométricos que denominé "geometría activa". Empieza actuando en el propio cuerpo del niño y en sus juguetes como sistemas objeto. Sobre estos sistemas se construye un sistema conceptual de transformación. Y pueden surgir muchos sistemas simbólicos posibles a partir del sistema conceptual.

Sólo un ejemplo: caminar a lo largo de segmentos y girando con el propio cuerpo en los ángulos de las esquinas resolvió el eterno problema de los estudiantes acerca de los ángulos exteriores de los triángulos.
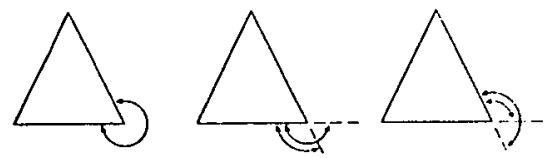

\section{Pregunta: ¿Cuál es el ángulo exterior?}

Si miramos la figura muerta, estamos perdidos. No es posible ninguna respuesta definitiva. Pero si trazamos con tiza un gran triángulo en el suelo y caminamos en torno a él, no hay duda sobre el significado del ángulo exterior: hay que girar con el pie delantero para alinearlo con el lado siguiente en cuanto se sobrepasa el vértice. El hecho evidente de que cuando se anda alrededor de un triángulo se acaba mirando en la misma dirección que al principio, da un significado dinámico, activo y vivo al hecho de que la suma de los ángulos exteriores de un triángulo es una vuelta completa $\left(360^{\circ}\right)$.

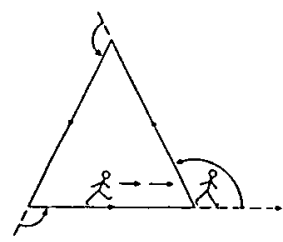

Respuesta: ;Basta con caminar alrededor del triängulo!

Pero entonces, ¿cuál es el significado de la afirmación de que la suma de los ángulos interiores es dos rectos (es decir, $180^{\circ}$ o media vuelta)? Basta con tratar de andar alrededor del triángulo siguiendo los ángulos interiores con el pie hacia atrás. Para sorpresa de muchos, se acaba mirando en dirección opuesta a la inicial. ¡Que nadie se pierda la diversión de la geometría activa!

Seymour Papert también había descubierto este tipo de geometría dinámica. En su libro de 1980 Mindstorms, habla de cómo los niños imitan a la tortuga del LOGO con sus propios cuerpos para poder programar una trayectoria circular. Denomina a esto "geometría corporal» $y$ «aprendizaje sintónico»:

El circulo de la tortuga es corporalmente sintónico en el sentido de que el círculo se relaciona firmemente con la sensación y el conocimiento que tienen los niños de su propio cuerpo 30 .

Pero para hacer geometría activa no se requiere un ordenador sofisticado o una versión bien desarrollada e interactiva de LOGO; parto del supuesto de que sólo hace falta un oído sensible para escuchar a niños nada sofisticados hablar con su propio lenguaje poco desarrollado, y una vista sensible para descubrir el sistema objeto culturalmente relevante. A partir de aquí se puede desarrollar una geometría activa, no sólo en el entorno de la Mathland del MIT, sino también en cada escuela primaria del país.

De nuevo, y en el lenguaje de Papert, abogo por una «sintonía cultural». $\mathrm{Pa}^{-}$ 
pert ilustra este concepto relacionando ángulos y navegación por medio de la tortuga del LOGO:

Una de las representaciones más difundidas de la idea de ángulo en las vidas de los norteamericanos contemporáneos se da en la navegación. Muchos millones de ellos navegan en barcos o aviones... La tortuga conecta la idea de ángulo con la navegación, actividad que está firme y positivamente enraizada en la cultura extraescolar de muchos niños. Y a medida que los ordenadores continúen extendiéndose por el mundo, la sintonía cultural de la geometría de la tortuga se hará más y más poderosa ${ }^{11}$.

No puedo juzgar con qué firmeza y positividad está enraizada la navegación en Norteamérica; en Colombia lo encuentro demasiado esotérico: ninguno de los niños de las escuelas públicas de Bogotá que conozco ha tenido esta experiencia. Quizá en la costa caribeña o del Pacífico de nuestro país pueda haber algunos niños que naveguen, en embarcaciones; pero ninguno de ellos tendrá la oportunidad de interactuar con las tortugás informáticas del entorno LOGO, al menos no antes del siglo XXI. No creo que debamos esperar tanto: abogo por la sintonía cultural, no sólo de la geometría, sino de todo sistema matemático; y no sólo en el entorno LOGO sino en cualquier escuela, por muy apartada que esté de yates $\mathbf{u}$ ordenadores. Empecemos a conectar cada idea o sistema matemático con una actividad firme y positivamente enraizada en la cultura extraescolar.

\section{CONCLUSIONES}

Este viaje antropológico a las regiones inexploradas de las escuelas de primera enseñanza de Colombia cambió mi manera de pensar sobre el aprendizaje de las matemáticas: reveló que el aprendizaje de las matemáticas puede ser tan dependiente de la cultura como el aprendizaje de la literatura o la historia, y no sólo en el nivel lingüístico o simbólico. La aparente no-historicidad y no-culturalidad de las matemáticas es una fantasía de una mente adulta que ha alcanzado la meseta del pensamiento formal y ha reprimido el razonamiento condicionado por la historia y dependiente de la cultura de todos los niños y la mayoría de los adultos, al menos cuando estos adultos no tratan de "pensar matemáti- camente»; es decir, prácticamente en todo momento.

El problema es que el enseñante de matemáticas es uno de los pocos adultos que trata de «pensar matemáticamente"; y el autor de libros de texto de matemáticas aún es peor. El principal obstáculo con que se ha enfrentado la reforma experimental colombiana no reside, ciertamente, en el nivel de los niños: a ellos les encanta. Reside en el nivel de los enseñantes, sobre todo en los encargados de la formación de los enseñantes y en los inspectores. Ellos saben todas las respuestas. Ellos están seguros de que la matemática es el lenguaje universal. Creen que pueden evaluar objetivamente lo que los niños saben de las matemáticas. Creo que sólo evalúan lo que los niños recuerdan de estos sistemas simbólicos desercarnados que la mayoría de los enseñantes piensa que son las matemáticas.

Un maestro venerado e investigador de la matemática, Edward G. Begle, pensó hasta el último momento de su vida que los sistemas matemáticos eran sistemas formales y simbólicos. Su estudio de la investigación de la enseñanza de las matemáticas atinó con la noción de sistemas matemáticos, pero la filosofía formalista que predominaba en la matemática le llevó a identificar erróneamente los sistemas matemáticos en el nivel conceptual con los sistemas simbólicos formales y, naturalmente, a olvidar por completo los sistemas objeto ${ }^{12}$. La mayor parte de la investigación sobre la enseñanza de las matemáticas parte de la misma confusión e ignora por completo los sistemas objeto. Mi predicción es que esta investigación avanzará poco o nada a partir de ahora.

Quizá los métodos alternativos de enseñanza puedan acelerar el aprendizaje de los procedimientos simbólicos; pero el investigador no sabrá por qué. Los métodos nuevos basados en los modelos de la Inteligencia Artificial pasarán a un primer plano, pero hasta el momento las máquinas sólo pueden ejecutar algoritmos simbólicos. La comprensión conceptual, la transferencia a nuevas situaciones y la producción de nuevos conceptos matemáticos a partir de sistemas objeto seguirán en la sombra.

Mientras los sistemas objeto matemáticos y prematemáticos sean ignorados, los investigadores, los autores de libros de texto y los enseñantes seguirán aferrándose al crrónco presupuesto de 
que los niños no saben nada de matemáticas cuando entran en la escuela. ¿Qué enseñante de lenguaje partirá del supuesto de que los niños de seis años no saben nada de Inglés o de Castellano cuando entran en la escuela? Quizá los maestros de institutos especiales de educación para sordomudos. Mientras los enseñantes sigan pensando que los niños son matemáticamente sordomudos, la enseñanza de las matemáticas, sean «básicas» o "modernas», está condenada a llegar únicamente al 10 por ciento que consigue construir sus propios sistemas conceptuales a pesar de sus maestros, desenredando por su cuenta el laberinto de sistemas simbólicos despojados de todo su contenido cultural e imaginativo. Cuando han construido sus sistemas conceptuales, pueden sintonizar fácilmente sus receptores con la onda del maestro, seguir aprendiendo matemáticas y empezar a dejar a sus compañeros muy atrás. El enseñante sólo enseñará a los estudiantes privilegiados, creando en el resto de ellos la «fobia a las matemáticas" tan bien descrita por Papert ${ }^{13}$.

Deberá realizarse con detalle un análisis serio de todos los sistemas matemáticos encontrados en el currículo escolar antes de diseñar un nuevo programa de investigación, un nuevo libro de texto $e$ incluso una nueva lección o actividad escolar en matemáticas. He aquí algunas de las preguntas que se están investigando en Colombia y que deberían investigarse en otros lugares para hacer que esta meta utópica sea una realidad:

1. ¿Qué experiencia con sistemas concretos, sean matemáticos o protomatemáticos, poseen ya los niños en su cultura extraescolar?

2. ¿Cómo podemos delimitar estos sistemas objeto culturalmente familiares para establecer sus componentes, sus procedimientos, sus relaciones?

3. ¿Qué palabras, imágenes, símbolos, señales, gestos, ..., emplean los ninos y los adultos para hablar de los componentes, los procedimientos y las relaciones de estos sistemas objeto concretos?

4. Qué transformaciones, acciones, procedimientos u operadores que actúan sobre estos sistemas objeto constituyen la materia prima para la construcción de un nuevo sistema conceptual?
5. ¿Qué significa componer, o aplicar sucesivamente, estos operadores a componentes objeto? ¿Qué otras combinaciones u operaciones conceptuales pueden realizarse en los operadores que ahora forman los componentes del nuevo sistema conceptual?

6. ¿Qué relaciones existen entre estos operadores?

7. ¿Qué sistemas simbólicos se han desarrollado en la cultura local, en la cultura de la clase media dominante o en la literatura matemática para representar estos operadores, los procedimientos sobre ellos y sus relaciones en el nuevo sistema conceptual?

8. ¿Qué procedimientos se emplean para manipular y combinar estos símbolos en los correspondientes sistemas simbólicos (algoritmos)?

9. ¿Qué relaciones existen entre los símbolos de cada sistema simbólico y entre los símbolos de diferentes sistemas simbólicos desarrollados para el mismo sistema conceptual?

10. Colisionan las notaciones y los algoritmos usuales en los libros de texto con el manejo concreto, conceptual o simbólico de los sistemas objeto, conceptuales o simbólicos culturalmente familiares?

Por tanto, sólo se emplean dos herramientas conceptuales sencillas para analizar las totalidades matemáticas. Podríamos pensar en ellas como dos prismas triangulares que descomponen la luz blanca de la totalidad matemática que se analiza; el primer prisma muestra tres niveles de sistemas: sistemas objeto concretos, sistemas conceptuales y sistemas simbólicos; el segundo prisma muestra tres tipos diferentes de entidades dentro de cada sistema: componentes, procedimientos y relaciones. Cuando la imagen global se extiende en detalle y se comprende en su complejidad, la investigación educativa y el diseño de currículos en este aspecto determinado de las matemáticas tendrá un marco de referencia definido en el que destacarán la dependencia cultural directa de los sistemas simbólicos, la dependencia cultural indirecta de los sistemas conceptuales $y$, por encima de todo, la dependencia cultural determinante de los sistemas objeto concretos. 
Notas

1 Citado con autorización. Vygotsky, L. S., Mind in Society. The Development of Higher Psychological Processes. Harvard University Press, Cambridge, Londres, 1978, p. 84.

2 Véase, por ejemplo:

Begle, E. G.: Critical Variables in Mathematics Education: Findings from a Survey of the Empirical Literature. MAA-NCTM, Washington, DC, 1989.

Fennema, E. (ed.), Mathematics Education Research: Implications for the '80s. NTCM-Reston, 1981.

Suppes, P. (ed.), The Impact of Research on Education. NAE, Washington, DC, 1978.

${ }_{3}$ Un primer borrador de la versión más general fue publicado por el equivalente colombiano de la NSF, «COLCIENCIAS» en su revista Ciencia, Tecnología y Desarrollo, Vol. $4, \mathrm{n}^{\circ} 4$ (octubre-diciembre 1980), pp. 463-82, bajo el título: "Teoría de Sistemas y Metodologías Científicas*. Un informe más completo fue publicado por la Sede Central de la OAS en Washington, DC y el Ministerio de Educación Colombiano: Ministerio de Educación Nacional, Oficina de Documentación, CAN, Bogotá, DE Colombia.

${ }^{4}$ La versión especial para el currículo de matemáticas ha sido publicada por el Ministerio de Educación como un folleto para enseñantes de maestros en varias ediciones desde 1978. Fue presentado como ponencia en la V Conferencia Internacional sobre Enseñanza de las Matemáticas celebrado en Campinas, Brasil, en febrero de 1979. Esta ponencia fue publicada más tarde en la revista de enseñantes de matemáticas editada por la Universidad Nacional de Colombia, Notas de Matemáticas, n. ${ }^{\circ} 10$ (1980), pp. 1-14. Su título es «El concepto de Sistema como Clave del Currículo de Matemáticas».

${ }_{5}$ Como se ha afirmado antes, el poder de hacer que los agujeros sean visibles es el principal uso de la teoría. El simple instrumento teórico de dividir sistemas como se dice me permitió ver lo incompleto de la división usual tipo Bourbaki de las estructuras en tres «estructuras madre": algebraica, ordinal y topológica. En primer lugar, Bourbaki confunde sistemas y estructuras; en segundo lugar, las estructuras algebraicas son aquellas en las que las únicas estructuras son las que se definen ímplicitamente por los procedimientos; pero las estructuras ordinales y topológicas son sólo dos ejemplos -y no son los únicos-de estructuras en las que no se dan procedimientos explícitos. Deberían denominarse estructuras (puramente) relacionales. Las estructuras ordinales sólo tienen relaciones de orden (binarias); las estructuras topológicas sólo tienen relaciones de vecindad (puede pensarse en las cercanías como relaciones unarias: $V(x)$ se cumple si $V$ es un vecino abierto de $x$; 0 como relaciones binarias: $V(x, y)$ se cumple si $V$ es un vecino abierto tanto de $\mathrm{x}$ como de y). Pero hay muchas otras estructuras relacionales no clasificables como algebraicas, ordinales o topológicas. Por ejemplo, un sistema de puntos con el intercalamiento y la colinealidad como relaciones (ternarias); o un sistema de rectas con el paralelismo y la perpendicularidad como relaciones (binarias). Son puramente relacionales, pero no son ni ordinales ni topológicas. Esta laguna en el sistema de Bourbaki era invisible sin la teoria.

"Se trata de un caso típico del concepto dialectal de "Aufhebung»: superar, tanto en el sentido de hacer que algo sea obsoleto como de recuperar lo mejor, el fondo, la esencia de ello. Los buenos ejemplos de sistemas objeto son difíciles de determinar con precisión, porque se olvidan fácilmente cuando ya se ha construido el sistema conceptual. Y se puede jurar que no había nada más profundo que los sistemas que ahora parecen concretos, pasivos y naturales. Es esencial darse cuenta de que un sistema conceptual dado puede aparecer como una construcción única por encima de una pluralidad de sistemas objeto en el nivel arcaico.

7 Citado con autorización. Vygotsky, op. cit., p. 89.

8 Recientemente, se ha publicado en castellano un estudio preliminar de las conjunciones dependientes del tiempo y de su empleo en el habla ordinaria en: Vasco, Carlos E., *Conectivas Secuenciales y la Formalización del Lenguaje Ordinario". Matemática-Enseñanza Universitaria (Bogotá), n. 27 (junio de 1983), pp. $12-23$

' Cardano, Girolamo: The Great Art or the Rules of Algebra. Traducido y editado por T. R. Witmer. The MIT Press, Cambridge, MA, 1968. Véanse las pp. 9, 11 y 29.

${ }^{10}$ Vygotsky, op.cit., p. 56.

$"$ Citado con autorización. Papert, Seymour. Mindstorms. Computers and Powerful Ideas. Basic Books. Inc. Nueva York, NY, 1980, pp. 58 y 63.

i2 Ibid., p. 63.

13 Véase Begle, E. G.: Critical Variables in Mathematics Education: Findings from a Survey of the Empirical Literature. Mathematical Association of America National Council of Teachers of Mathematics. Washington, DC, 1979. Begle murió en 1978 a la edad de 63 años. En la introducción a su libro (pp. 1-3) estudia la noción básica de sistema matemático. Pero reduce los sistemas matemáticos a nuestro nivel superficial: los sistemas simbólicos.

14 Papert, op cit., Capitulo II: «Mathophobia: The Fear of Learning» pp. 38-54. 


\section{El aprendizaje de las matemáticas elementales como proceso condicionado por la cultura. C. Vasco. \\ $C L \mathcal{E} E, 1990,6$, pp. 5-25}

Datos sobre el autor: Carlos Vasco es profesor de Matemáticas en la Universidad Nacional de Colombia. Ha publicado numerosos trabajos sobre enseñanza de la lógica y de la ciencia y una serie de libros sobre la aplicación de la teoría general de sistemas al cambio educativo.

Articulo original: "Mathematics as a culturally conditioned process". Este artículo forma parte de una compilación de trabajos realizada por M. I. White y S. Pollak sobre los aspectos culturales que inciden en el proceso de enseñanza-aprendizaje en el marco del Proyecto Potencial Humano. Fue publicado en inglés por Routledge \& Kegan Paul y su versión en castellano ha aparecido en Visor en 1990 bajo el título $L a$ transición cultural. A ambos editores agradecemos su autorización para publicarlo en $C L E E$. Traducción de Genis Sánchez.

(C) de todos los artículos. Deberá solicitarse por escrito autorización de CL\&E y de los autores para el uso en forma de facsímil, fotocopia o cualquier otro medio de reproducción impresa. CL\&E se reserva el derecho de interponer acciones legales necesarias en aquellos casos en que se contravenga la ley de derechos de autor. 


\section{FE DE ERRORES}

- En la ficha final (pág. 87) del artículo titulado «Sobre la didáctica del texto expositivo" que apareció en el número 3-4 de $C L E E$, aparece un dato incorrecto: la dirección de la Consellería de Cultura es Avda. de Campanar 32 y no 124.

- En el número 3-4 de $C L E E$ aparece un artículo de Antonio Bautista «El uso de los medios desde los modelos del curriculum» (pág. 39) en el que se omitió involuntariamente un esquema al que se hace referencia en el texto (pag. 41). Este esquema era el siguiente:

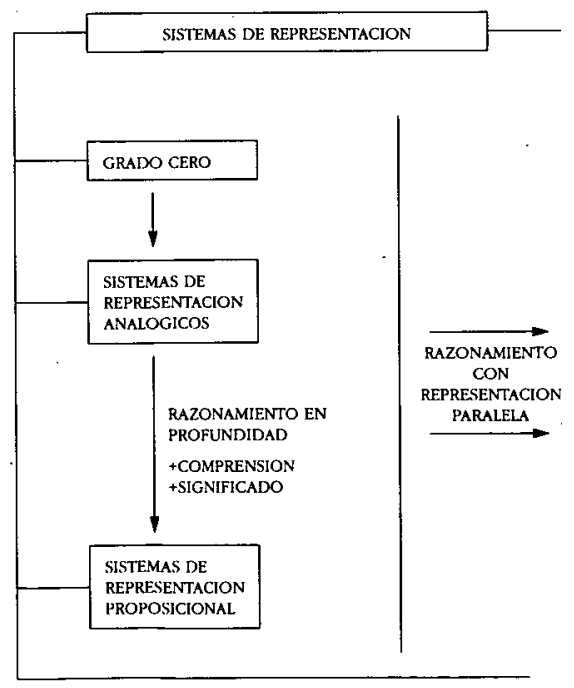

- En el número 5 de $C L E E$ aparece una reseña en la cual hay dos errores: el título que aparece del libro es el de la versión chilena. La versión que ha aparecido en España (Madrid: Visor, 1990) lleva por título: La enseñanza de la escritura. Bases teóricas y prácticas (Manual).

Por otro lado, la reseña fue realizada por Helena Huerta, a quien pedimos disculpas por la omisión. 